\title{
ERRATUM
}

\section{Hanlong LIU, Xuanming DING \\ Propagation characteristics of transient waves in low-strain integrity testing on cast-in-situ concrete thin-wall pipe piles}

(C) Higher Education Press and Springer-Verlag 2009

Front. Archit. Civ. Eng. China 2009, 3(2): 180-186

Due to typesetting production errors, some mistakes were made. The Editorial Office regrets these errors.

(1) The title of Fig. 5 should be "Velocity response spectrum at different points on top of pile";

(2) The title of Fig. 7 should be "Velocity response spectrum of pipe piles with different impulse widths ".

The online version of the original article can be found at 10.1007/s11709-009-0026-1

Translated from Chinese Journal of Geotechnical Engineering, 2008, 30 (3): 414-419 [译自: 岩土工程学报]

Hanlong LIU ( $₫)$, Xuanming DING

Key Laboratory of Ministry of Education for Geomechanics and Embankment Engineering, Hohai University, Nanjing 210098, China Geotechnical Research Institute, Hohai University, Nanjing 210098, China

E-mail: hliu@hhu.edu.cn 